\title{
The second wave of 2009 pandemic influenza A(H1N1) in New Zealand, January-October 2010
}

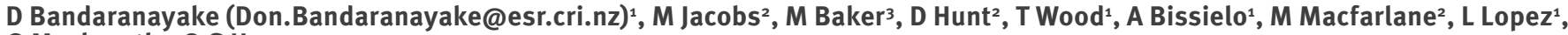

G Mackereth ${ }^{1}$, Q S Huang ${ }^{1}$

1. Institute of Environmental Science and Research, National Centre for Biosecurity and Infectious Disease, Upper Hutt, New Zealand

2. Ministry of Health, Wellington, New Zealand

3. Wellington School of Medicine and Health Sciences, University of Otago, Wellington, New Zealand

Citation style for this article:

Bandaranayake D, Jacobs M, Baker M, Hunt D, Wood T, Bissielo A, Macfarlane M, Lopez L, Mackereth G, Huang QS. The second wave of 2009 pandemic

influenza A(H1N1) in New Zealand, January-October 2010. Euro Surveill. 2011;16(6):pii=19788. Available online: http://www.eurosurveillance.org/ViewArticle. aspx?Articleld=19788

Article published on 10 February 2011

This paper uses data from multiple surveillance systems to describe the experience in New Zealand with the second complete wave of pandemic influenza $A\left(H_{1} N_{1}\right) 2009$ in 2010. Measures such as hospitalisation rates suggest the overall impact of influenza $A\left(\mathrm{H}_{1} \mathrm{~N}_{1}\right)_{2009}$ in 2010 was between half and two thirds that of the first wave in 2009. There was considerable regional and sub-regional variation with a tendency for higher activity in areas that experienced low rates in 2009. Demographic characteristics of the second wave were similar to those in $\mathbf{2 0 0 9}$ with highest rates seen in children under the age of five years, and in indigenous Māori and Pacific peoples. Hospital services including intensive care units were not under as much pressure as in 2009. Immunisation appears to have contributed to the reduced impact of the pandemic in 2010, particularly for those aged 60 years and older.

\section{Introduction}

Between April and December 2009, New Zealand experienced the first wave of the influenza $A\left(\mathrm{H}_{1} \mathrm{~N}_{1}\right) 2009$ pandemic, with 3,211 laboratory-confirmed case notifications, 1,122 hospitalisations and 48 deaths [1]. The numbers from April to August 2009 have been documented in the literature [1-5]. Subsequently, a national seroprevalence survey confirmed that the true extent of infection from the pandemic was much greater than indicated by surveillance data, with an estimated cumulative incidence of over 780,000 infections $(18.3 \%$ of New Zealanders) [6]. This survey utilised a randomly selected community-based sample from the $\mathrm{New}$ Zealand population aged over one year. It obtained 1,156 serum samples from populations enrolled in general practices in selected regions of the country and a further 527 samples from healthcare workers. In addition a baseline survey was conducted using 538 prepandemic samples collected for other reasons.

During the early months of 2010 the notifications of pandemic influenza $A\left(\mathrm{H}_{1} \mathrm{~N}_{1}\right)_{2009}$ cases dwindled to zero, until a few cases were notified in July. Influenza activity then increased and peaked in the middle of August 2010 with the pandemic influenza $A\left(\mathrm{H}_{1} \mathrm{~N}_{1}\right) 2009$ virus as the predominant strain [7]. The second wave of influenza $A\left(\mathrm{H}_{1} \mathrm{~N}_{1}\right)_{2} 2009$ again coincided with $\mathrm{New}$ Zealand's usual influenza season. This wave was of a similar duration with a lower peak than the first wave, but with significant regional variations - some areas that had relatively low influenza-like illness (ILI) activity or hospitalisations in 2009 experienced higher levels of influenza activity in 2010 [7]. For 2010, as of the middle of October we have seen 1,768 confirmed cases, including 732 hospitalisations and 15 confirmed deaths.

The eligibility policy for the 2010 trivalent influenza vaccine was extended to allow pregnant women, children under five years and obese individuals to receive subsidised vaccine. Individual's over 65 years and those with underlying health conditions were also eligible. A monovalent vaccine (CELVAPAN H1N1; Baxter) was made available for healthcare workers in February 2010. The trivalent (seasonal) vaccine became available in April. The uptake was low for the former while stocks had to be re-ordered for the trivalent vaccine in March 2010. The subsidised influenza immunisation programme ended on 30 September 2010. Since then, influenza vaccines have still been available for people who want to purchase them, but demand has been very low.

This report uses multiple surveillance sources to describe the second wave of pandemic influenza $\mathrm{A}\left(\mathrm{H}_{1} \mathrm{~N}_{1}\right)_{2009}$ in New Zealand and compare it with the first wave. These sources are described in a previous publication reporting on the first wave of the pandemic [2]. The aims are to compare incidence and impact of infection as well as timing and shape of the epidemic curve, to identify whether there are persisting or divergent regional patterns and whether vulnerable age and ethnic groups have changed, to assess whether the virus has changed, and to analyse the extent and impact of immunisation. The overall aim is to identify 
implications for minimising the public health impact of this virus, particularly for countries in the northern hemisphere in the future.

\section{Methods and data sources}

The following surveillance systems provide data on influenza disease burden, characteristics of the virus and immunisation coverage:

\section{Surveillance of influenza-like illness \\ by the Institute of Environmental \\ Science and Research based on data \\ from sentinel general practitioners}

There are 90 volunteer sentinel general practitioner (GP) practices distributed throughout the country. Normally sentinel surveillance operates in the winter period, from May to September. However, due to the pandemic, the sentinel system operated continuously from May 2009 to September 2010. The sentinel system defines a case of ILI as an acute respiratory tract infection characterised by an abrupt onset of at least two of the following: fever $\left[\geq 37^{\circ} \mathrm{C}\right]$, chills, headache, and myalgia [8]. Each general practice records the daily number of consultations for ILI and also collects three respiratory samples (nasopharyngeal or throat swab) per week from each of the first ILI patient seen on Monday, Tuesday and Wednesday. Consultation numbers and samples were sent to the World Health Organization (WHO) National Influenza Centre at the Institute of Environmental Science and Research (ESR) in Wellington and other hospital laboratories. Sentinel ILI rates are expressed as per population and not per total numbers of consultations. This system has been described in detail previously $[2,3]$.

\section{Surveillance of influenza-like illness}

by Healthstat based on data from sentinel general practitioners

CBG Ltd, a privately owned company contracted by the New Zealand Ministry of Health $(\mathrm{MoH})$, uses a core of 100 general practices throughout New Zealand to gather computerised information on ILI consultations on a weekly basis (Healthstat). Both the ESR and Healthstat surveillance use practices across the country, providing both a regional and national picture of ILI. However, samples for molecular analysis are not collected in the Healthstat system.

\section{Healthline}

Healthline is the national 24-hour triaged telephone health advice service provided by the $\mathrm{MoH}$ in New Zealand. All calls are answered by registered nurses with telenursing training and working within the Nursing Council's Professional Standards for Telenursing Practice [2]. The Healthline service uses a computerised triage algorithm for symptomatic callers and an electronic health topic library for general health information. Numbers of monitored ILI calls can be made available on a daily basis.
Notified cases

Influenza $\mathrm{A}\left(\mathrm{H}_{1} \mathrm{~N}_{1}\right)_{2009}$ became a notifiable disease in New Zealand on 30 April 2009. Notifications include those made through direct laboratory notification which is a legal requirement in New Zealand. Other sources of notifications are from clinicians in both primary and secondary care. Data are entered into the national database for notifiable diseases (Episurv). During 2010 and most of 2009, notification has largely been based on laboratory reporting of confirmed cases. Thus although notification data are useful for monitoring trends, they are a substantial underestimate of true community incidence of infection.

\section{Virological surveillance}

Virology swabs are collected through the ESR sentinel GP surveillance during the influenza season, as well as through year-round laboratory testing by the four regional virus diagnostic laboratories at Auckland, Waikato, Wellington and Christchurch Hospitals, and by the WHO National Influenza Centre at ESR. Laboratory identification methods include molecular detection by polymerase chain reaction or isolation of the virus [9]. Influenza viruses are typed and subtyped as influenza $A, B$, seasonal $A\left(\mathrm{H}_{1} \mathrm{~N}_{1}\right)$, seasonal $A\left(\mathrm{H}_{3} \mathrm{~N}_{2}\right)$, or $A\left(\mathrm{H}_{1} \mathrm{~N}_{1}\right) 2009$. Fluorometric neuraminidase inhibition assay is used for monitoring oseltamivir susceptibility [5].

\section{Hospitalisations (including intensive care)} Hospitalisations among confirmed cases of influenza $A\left(\mathrm{H}_{1} \mathrm{~N}_{1}\right) 2009$ notified to EpiSurv were reviewed by ESR throughout the second wave. In addition, the National Minimum Data Set (NMDS) that collates all hospital discharges (with diagnoses) was also used. Hospitalisation rates give a good indication of incidence trends for more severe cases nationwide. Such rates, while representing only a small proportion of all cases give a more complete picture of the progression of the pandemic than notifications. Information on cases of influenza $A\left(\mathrm{H}_{1} \mathrm{~N}_{1}\right)_{2009}$ admitted to intensive care units (ICU) and ICU bed occupancy were also obtained directly from ICUs as additional surveillance measures of healthcare utilisation.

\section{Deaths}

Mortality data for influenza $\mathrm{A}\left(\mathrm{H}_{1} \mathrm{~N}_{1}\right)_{2} 009$ are obtained from the standard processes for death certification and case notification, and from deaths referred to the Coroner. In addition, a Pandemic Influenza Mortality Review Committee was established in 2009 to review all deaths linked to the influenza $\mathrm{A}\left(\mathrm{H}_{1} \mathrm{~N}_{1}\right)_{2009}$ virus. $\mathrm{A}$ death associated with pandemic influenza $\mathrm{A}\left(\mathrm{H}_{1} \mathrm{~N}_{1}\right)_{2009}$ was defined as a person with confirmed pandemic influenza $\left.A_{(} \mathrm{H}_{1} \mathrm{~N}_{1}\right)_{2} 009$ infection determined from antemortem or post-mortem specimens, and who died from a clinically compatible illness or complications attributable to that infection. There should be no period of complete recovery between illness and death, and no alternative agreed-upon cause of death [10]. 
We estimated the case fatality and hospitalisation ratios for 2010 by first estimating the number of symptomatic influenza $\mathrm{A}\left(\mathrm{H}_{1} \mathrm{~N}_{1}\right)_{2009}$ infections in 2010. The number of symptomatic cases due to influenza $\mathrm{A}\left(\mathrm{H}_{1} \mathrm{~N}_{1}\right)_{2009}$ as estimated from the seroprevalence study was adjusted by the ratio of sentinel ILI activity for 2010 and 2009, and the proportion of viruses characterised as influenza $A\left(\mathrm{H}_{1} \mathrm{~N}_{1}\right) 2009$ in the two years. This gave an estimate of 176,308 symptomatic influenza $A\left(\mathrm{H}_{1} \mathrm{~N}_{1}\right) 2009$ cases in 2010.

\section{School absenteeism}

School absenteeism data represent numbers of pupils absent due to sickness or unexplained reasons. These are monitored on a daily basis by region through a database provided by the Ministry of Education using sentinel schools. The system commenced in 2010. 178 schools reported regularly, representing an average daily number of 64,911 students. Overall about $12 \%$ pupils are covered nationally. The data for 2010 are available for several regions. These results are not shown in this paper for reasons of brevity, lack of a valid baseline and the inability to compare with previous years.

\section{Immunisation coverage}

Estimations of total immunity prior to the onset of the second wave were based on the results of the seroprevalence study and estimated immunisation uptake levels [6]. These levels were taken as baseline levels for 2010, and estimated immunisation uptake levels were then included in the final estimate. Assuming that the immunisation uptake before the second wave was similar across age groups and independent of previous immune status, we estimated the age-specific immunity prior to the onset of the second wave as follows: Total immune = Immune (following first wave) + Immune (vaccinated) - Immune (first wave and vaccinated)

\section{Results}

\section{Epidemic curves}

Following a substantial increase in July 2010, the number of influenza $\mathrm{A}\left(\mathrm{H}_{1} \mathrm{~N}_{1}\right) 2009$ notifications peaked in mid-August and declined rapidly after that.

Figure 1 summarises the epidemic curves of the second wave of influenza $A\left(\mathrm{H}_{1} \mathrm{~N}_{1}\right)_{2009}$ in 2010 based on surveillance data from sentinel ILI, notifications, Healthline, hospitalisations and virological reporting systems in comparison with previous years. Results from these surveillance systems suggest that the pandemic in 2010 commenced one month later than in 2009 and had a significantly lower incidence.

Community surveillance of influenza-like illness (sentinel surveillance by the Institute of Environmental Science and Research)

The overall national ILI consultation rates in 2010 in the GP sentinel surveillance system show less influenza activity compared to 2009 (Figure 1a). As of the week 39 (ending 3 October 2010), the 2010 cumulative incidence rate of $1,019.9$ per 100,000 , was lower than that of 2,695.6 per 100,000 in 2009 (Table 1). The 2010 peak consultation rate of 152 per 100,000 , which was lower than that of 284.0 per 100,000 in 2009, occurred in week 33 (ending 22 August), four weeks later than the 2009 peak.

During this period from May to 3 October 2010 the highest ILI consultation rates were recorded among children and young adults. ILI consultation rates per 100,000 were 1,982.2 for infants, 2,163.7 for children aged one to four years, and 1,092 for children aged five to 19 years.

\section{Community surveillance of influenza- \\ like illness (Healthstat)}

Healthstat returns show some major differences compared to most other surveillance results. The epidemic curves for 2009 and 2010 in Figure 1b are of equal intensity. This might be a result of low sensitivity of the coding during 2009 (Table 1). It is known that in 2010 there was a concerted effort to improve the sensitivity of the data being collected with particular attention to coding by each of the practices involved.

\section{Notified cases}

Figure $1 \mathrm{C}$ shows the epidemic curves based on notifications for 2009 and 2010. These are all cases that have been notified and entered into the Episurv database from January to October 2010. The sharp increase in notifications during the second wave of influenza $\mathrm{A}\left(\mathrm{H}_{1} \mathrm{~N}_{1}\right) 2009$ commenced four weeks later than during the first wave. Following a substantial increase in July 2010, the number of influenza $A\left(\mathrm{H}_{1} \mathrm{~N}_{1}\right) 2009$ notifications peaked in week 33 (ending 22 August) with 367 cases, and then declined to less than 10 per week by the first week in October 2010. From January to 24 October 2010, a total of 1,782 cases of influenza $\mathrm{A}\left(\mathrm{H}_{1} \mathrm{~N}_{1}\right) 2009$ were notified, including 1,758 confirmed cases and 24 probable cases (Table1).

\section{Healthline}

The number of calls to Healthline for ILI during 2010 were lower than for 2009 (Figure 1d). The total number of triaged calls that were symptomatic for ILI gave the best indication of the impending second wave. Healthline calls increased in mid-June, two to three weeks before the other surveillance systems.

Hospitalisations and admissions to intensive care Hospitalisation rates in 2010 were considerably below the peak national rates for 2009, and declined rapidly (Figure 1e). As of 15 October the total number of hospital admissions with confirmed influenza $A\left(\mathrm{H}_{1} \mathrm{~N}_{1}\right)_{2009}$ $(n=732)$ was just over $72 \%$ of the total for the same period in $2009(n=1,011)$ while the number of ICU admissions was $87.4 \%$ of 2009 admissions ( $n=104$ and 119). The ICUs did not report unusually high levels of bed occupancy during the 2010 influenza wave. The hospitalisation ratio in 2010 (number hospitalised per symptomatic infections) was 415.2 cases per 100,000 . This 
was much higher than the ratio of 287 per 100,000 in 2009. Using total hospitalisations as the denominator from the NMDS, the ICU ratios in 2010 and 2009 were $14.5 \%$ and $10.6 \%$, respectively, of all hospitalisations.

\section{Deaths}

From 1 January to 15 October 2010, 20 deaths were reported as linked to pandemic influenza $A\left(\mathrm{H}_{1} \mathrm{~N}_{1}\right) 2009$
[8]. Fifteen of these deaths have so far been confirmed as being due to influenza $A\left(\mathrm{H}_{1} \mathrm{~N}_{1}\right)_{2009}$. Most deaths occurred in the age group 20 years and older. The 15 confirmed deaths due to influenza $A\left(\mathrm{H}_{1} \mathrm{~N}_{1}\right) 2009$ in 2010 give a case fatality ratio of 8.5 per 100,000 (15 of $176,308)$. This is similar to the one calculated for 2009: 9.0 per 100,000 . The median age of the fatal cases was 50 years in 2010 and 40 years in 2009.

\section{FIGURE 1}

National influenza surveillance data, New Zealand, 2008-10

A. ILI consultation rates (ESR) 2008-10

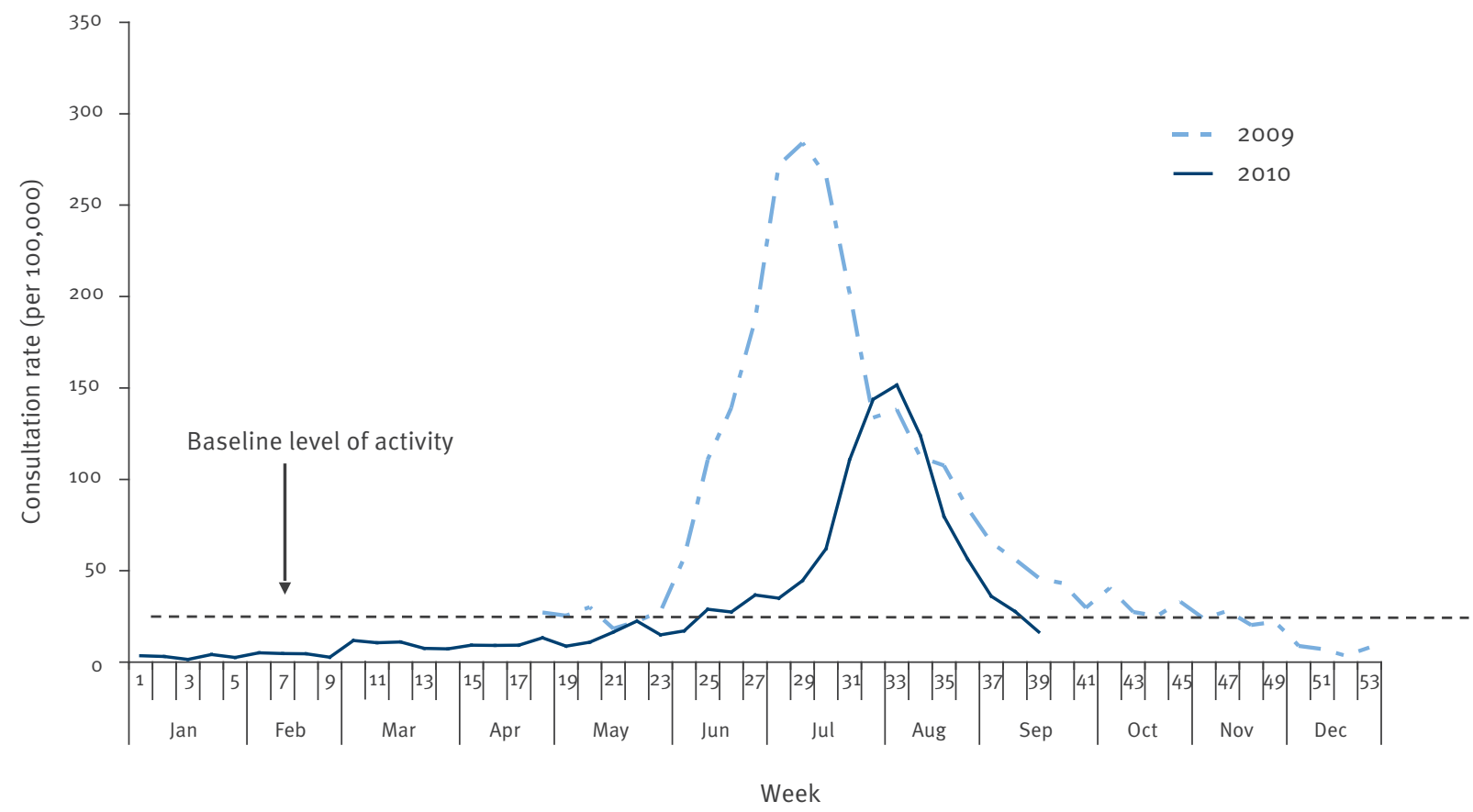

B. ILI consultation rates (Healthstat) 2008-10

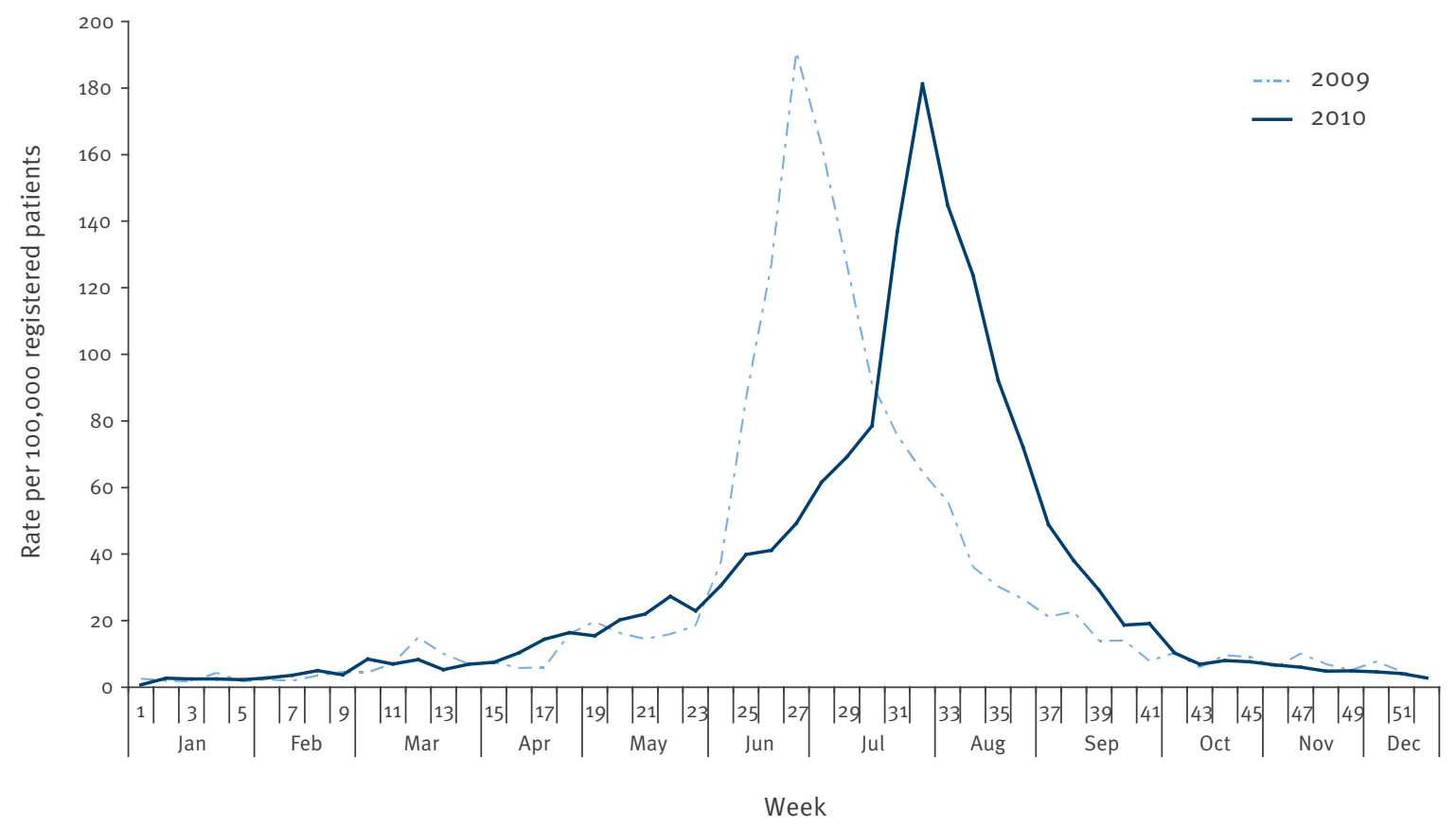

Data source: From responding practices of Original HealthStat GP practice panel. 
C. Influenza A(H1N1)2009 notifications 2009-10

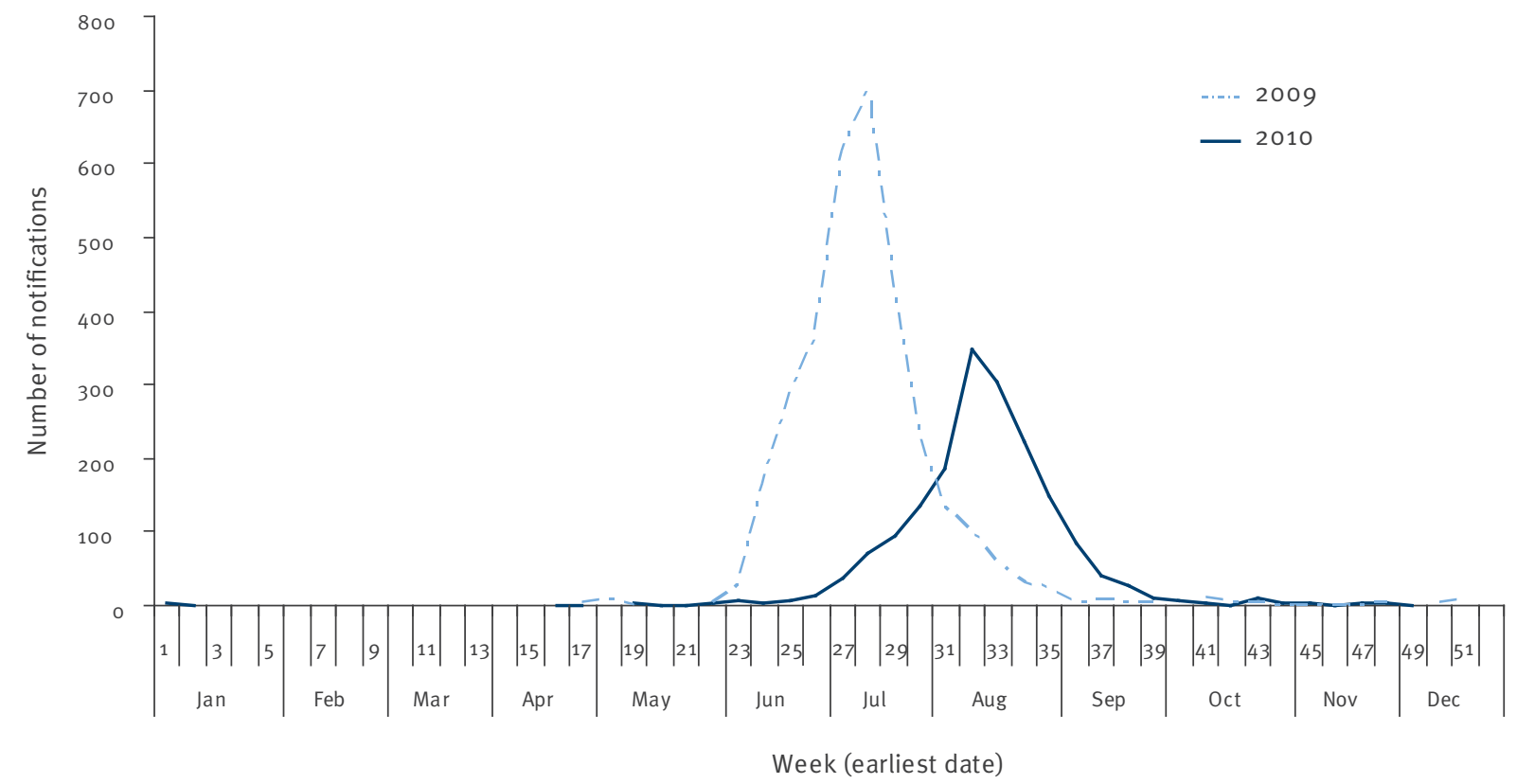

D. Healthline ILI calls, 2009-10

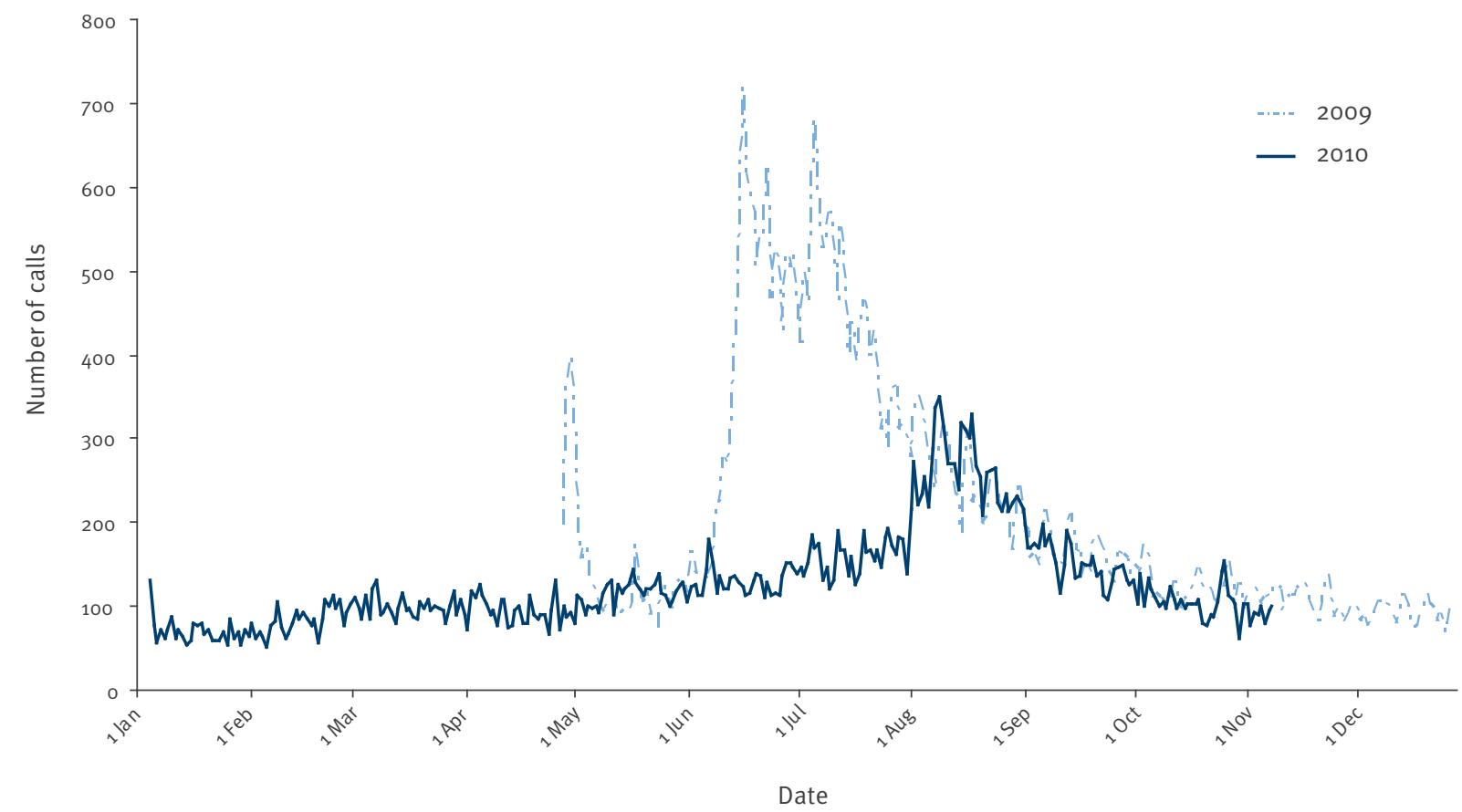


E. Hospitalisations 2009-10

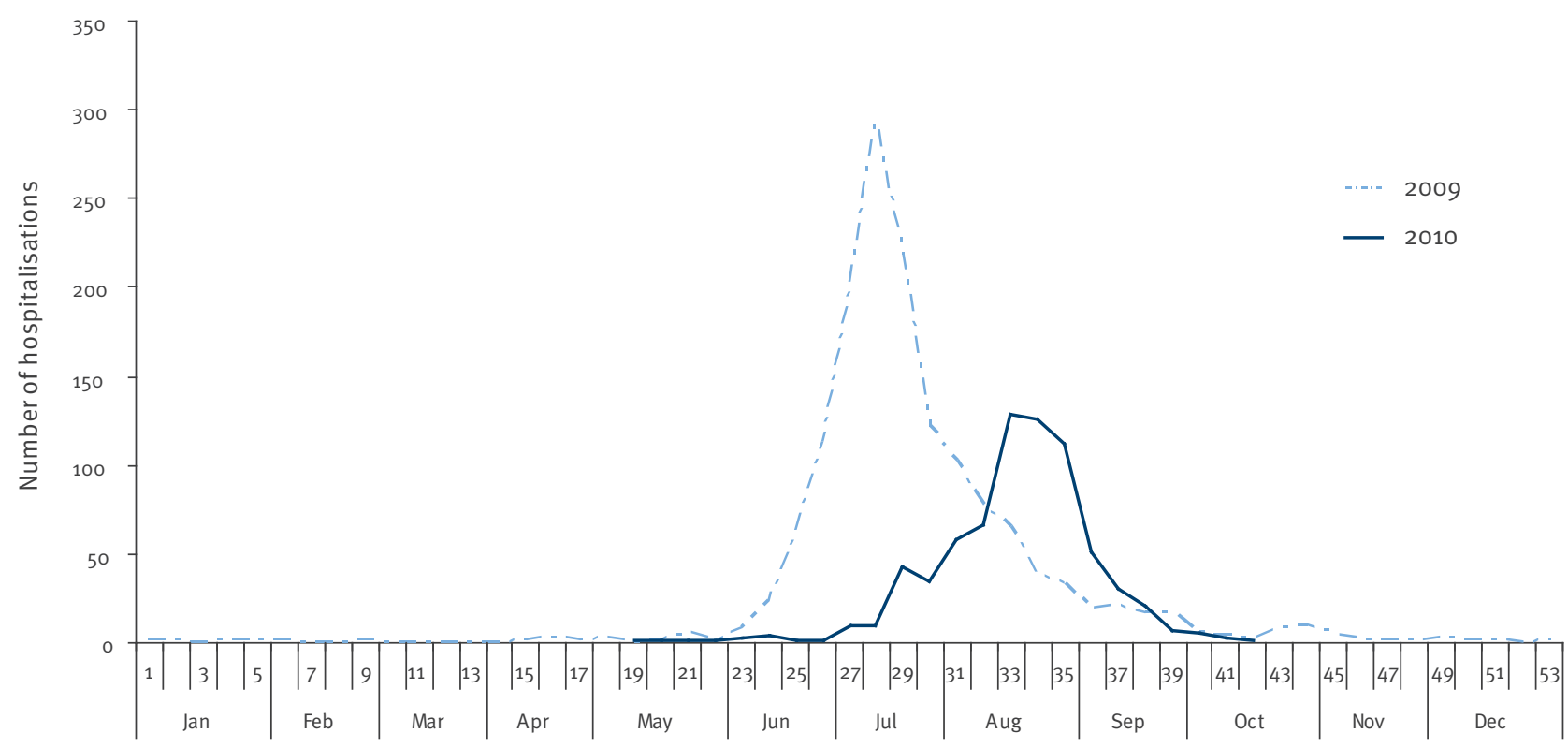

Week

F. Virological surveillance 2009-10

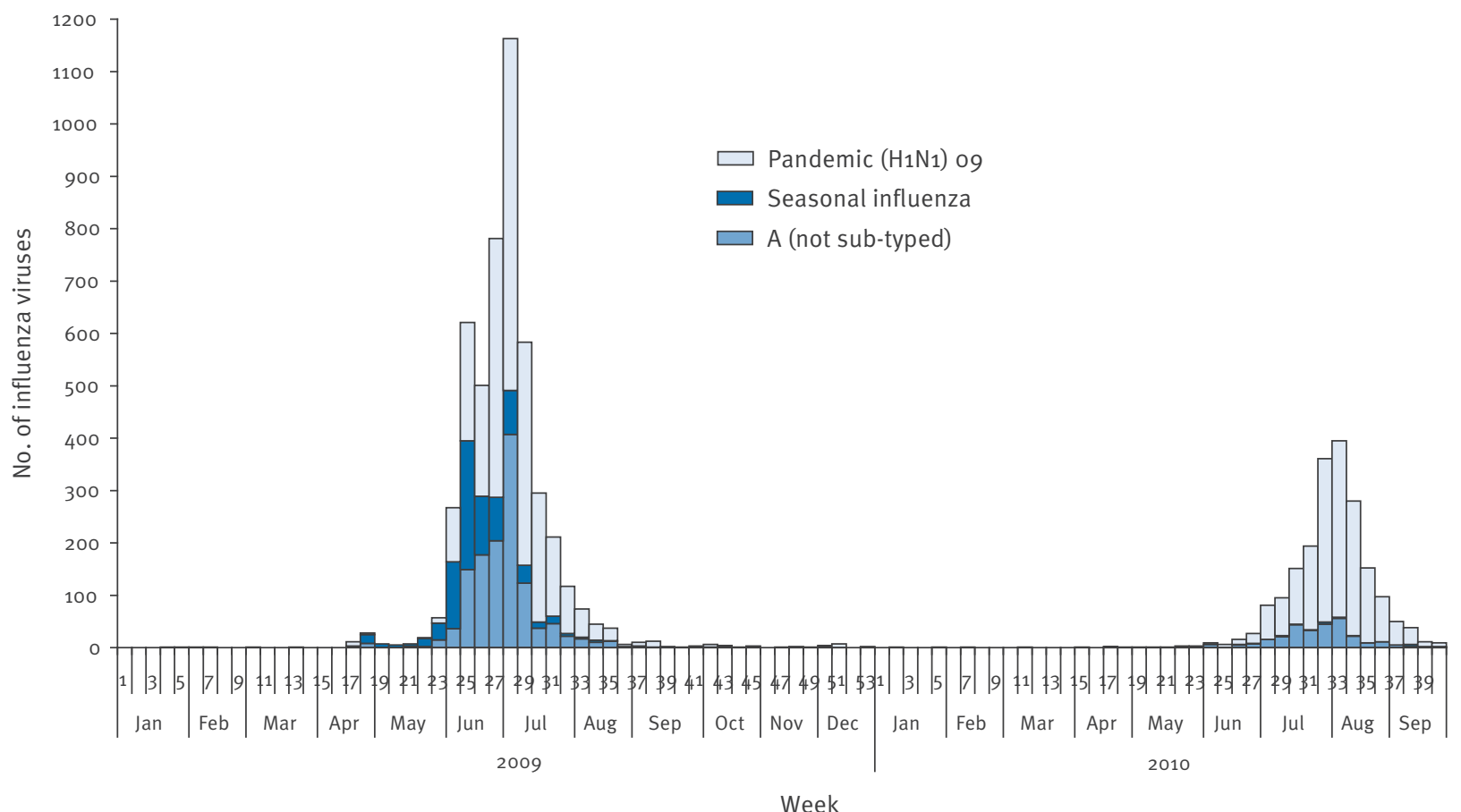

2010 data only up to week 39 (sentinel surveillance only).

ESR: Institute of Environmental Science and Research; ILI: influenza-like illness. 
Virological surveillance

Results of virological surveillance using samples from sentinel GPs and hospitals for 2010 and 2009 are shown in Figure 1e. As of the week ending 3 October 2010, pandemic influenza $A\left(\mathrm{H}_{1} \mathrm{~N}_{1}\right) 2009$ was the predominant strain $(84.5 \%, 1,684$ of 1,992$)$ including 392 pandemic influenza $A /$ California/7/2009( $\left.\mathrm{H}_{1} \mathrm{~N}_{1}\right)$-like strains, followed by not subtyped influenza $A(n=290)$, influenza $B$ $(n=9)$ including four B/Brisbane/6o/2008-like strains,

\section{TABLE 1}

Cumulative incidence of influenza-like illness and influenza A(H1N1)2009 cases, and viruses, New Zealand, 2009-10 (mid-October)

\begin{tabular}{|c|c|c|c|}
\hline \multirow[t]{2}{*}{ Surveillance system } & \multirow[t]{2}{*}{ Event } & \\
\hline & & \multicolumn{2}{|c|}{\begin{tabular}{c|c} 
Cumulative incidence per 100,000 (number of cases) \\
2009 & 2010
\end{tabular}} \\
\hline Sentinel GP (ESR) ${ }^{a}$ & ILI case & $2,695.6$ & $1,019 \cdot 9$ \\
\hline Sentinel GP (Healthstat) ${ }^{\mathrm{a}}$ & ILI case & 462.9 & 521.9 \\
\hline Healthline & ILI call & 987.9 & 820.4 \\
\hline Notifications $^{\mathrm{b}}$ & Influenza $\mathrm{A}\left(\mathrm{H}_{1} \mathrm{~N}_{1}\right) 2009$ case & $74 \cdot 5(3,214)$ & $40.4(1,768)$ \\
\hline Hospitalisations (notification data) ${ }^{\mathrm{b}}$ & $\begin{array}{c}\text { Influenza } \mathrm{A}\left(\mathrm{H}_{1} \mathrm{~N}_{1}\right) 2009 \text { case } \\
\text { hospitalised }\end{array}$ & $23 \cdot 5(1,016)$ & $16.7(732)^{c}$ \\
\hline Hospitalisations (NMDS) & Influenza $\mathrm{A}\left(\mathrm{H}_{1} \mathrm{~N}_{1}\right) 2009$ case & $26.0(1,122)$ & $16.4(717)$ \\
\hline ICU admission & Influenza $A\left(\mathrm{H}_{1} \mathrm{~N}_{1}\right) 2009$ case & 2.8 (119) & $2.4(104)$ \\
\hline Deaths (mortality reporting system) & Influenza $\mathrm{A}\left(\mathrm{H}_{1} \mathrm{~N}_{1}\right) 2009$ case & $1.1(48)$ & $0.34(15)$ \\
\hline Surveillance system & Virus type & \multicolumn{2}{|c|}{ Percentage of total influenza viruses (number of viruses) } \\
\hline Virological surveillance - influenza $\mathrm{A}\left(\mathrm{H}_{1} \mathrm{~N}_{1}\right) 2009^{\mathrm{d}}$ & Influenza $\mathrm{A}\left(\mathrm{H}_{1} \mathrm{~N}_{1}\right) 2009$ virus & $63.6 \%(395)$ & $75.9 \%(274)$ \\
\hline \multirow{3}{*}{$\begin{array}{l}\text { Virological surveillance - seasonal influenza } \\
(A \text { and } B)^{d}\end{array}$} & $\mathrm{~A}\left(\mathrm{H}_{1} \mathrm{~N}_{1}\right)$ virus & $15.8 \%(98)$ & $0 \%(0)$ \\
\hline & $\mathrm{A}\left(\mathrm{H}_{3} \mathrm{~N}_{2}\right)$ virus & $7.6 \%(47)$ & $0.8 \%(3)$ \\
\hline & B virus & $0.5 \%(3)$ & $0.3 \%(1)$ \\
\hline
\end{tabular}

ESR: Institute of Environmental Science and Research; GP: general practitioner; ICU: intensive care unit; ILI: influenza-like illness; NMDS: National Minimum Data Set.

a Data for surveillance week ending 6 May to week ending 30 September.

${ }^{b}$ Notified to Episurv for 2010 up to 15 October 2010.

c 65 hospitalised of 97 cases in pregnant women.

${ }^{d}$ The percentages represent proportions of the total number of viruses identified. These figures are ESR sentinel data, and do not include nonsentinel sources.

\section{FIGURE 2}

Laboratory-confirmed pandemic influenza A(H1N1)2009 hospitalisation rates per 100,000 by District Health Board of domicile, New Zealand, 2009 versus 2010a

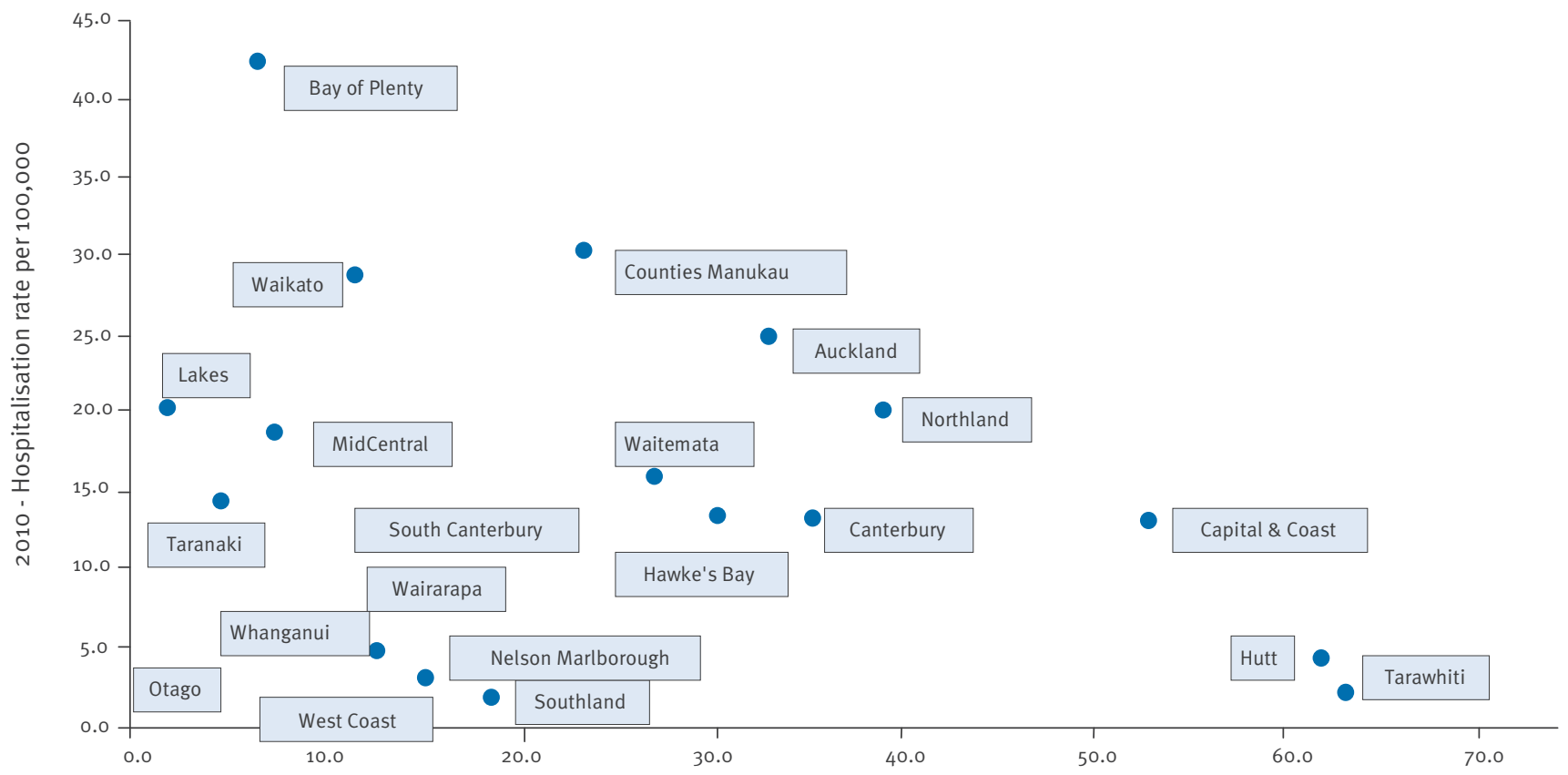

2009 - Hospitalisation rate per 100,000

a The full year 2009 (first pandemic wave) is compared with 2010 until 14 October (second pandemic wave). 
and seasonal influenza $\mathrm{A}\left(\mathrm{H}_{3} \mathrm{~N}_{2}\right)(\mathrm{n}=9)$ including two $\mathrm{A} /$ Perth/16/2009 ( $\left.\mathrm{H}_{3} \mathrm{~N}_{2}\right)$-like strains. No non-pandemic influenza $A\left(\mathrm{H}_{1} \mathrm{~N}_{1}\right)$ virus has been isolated in 2010, in contrast to 2009 when it was the dominant virus before influenza $A\left(\mathrm{H}_{1} \mathrm{~N}_{1}\right)_{2009}$ became established.

Most of the New Zealand isolates were antigenically and genetically closely related to the pandemic influenza $A\left(H_{1} N_{1}\right) 2009$ vaccine candidate $A / C a l i f o r n i a / 7 / 2009-$ like strain. In addition, 280 influenza $A\left(\mathrm{H}_{1} \mathrm{~N}_{1}\right) 2009$ isolates were subjected to the fluorometric neuraminidase inhibition assay and the results showed that they were all sensitive to oseltamivir.

\section{Cumulative incidence of}

influenza A(H1N1)2009

Table 1 reports the cumulative incidence of ILI and influenza $A\left(\mathrm{H}_{1} \mathrm{~N}_{1}\right) 2009$ cases for 2010

up to the end of October and compares this with the total year 2009. Both periods cover the complete pandemic waves. The data show that the proportion of hospitalised cases admitted to ICUs has been higher in 2010 (14.5\%) compared with 2009 (10.6\%).

\section{Regional patterns}

We observed heterogeneous distribution of pandemic influenza $\mathrm{A}\left(\mathrm{H}_{1} \mathrm{~N}_{1}\right) 2009$ among different geographical locations in New Zealand. In particular, some regions (mainly small urban and rural areas) that had relatively low ILI activity in 2009 experienced higher levels of activity during the second wave in 2010. For example, eight of the 20 District Health Boards (DHBs) reported weekly GP ILI consultation rates higher than those seen last year: Waikato, Bay of Plenty, Tairawhiti, Taranaki, Hawke's Bay, Wairarapa, West Coast and South Canterbury. Six DHBs hospitalised more cases with pandemic influenza $A\left(\mathrm{H}_{1} \mathrm{~N}_{1}\right) 2009$ this year than for the whole of the 2009 year: Counties Manukau, Waikato, MidCentral, Bay of Plenty, Taranaki and Lakes.

Figure 2 compares the DHBs' hospitalisation rates in 2010 with such rates in 2009. The scattergram gives a correlation coefficient of -0.20 indicating that in general DHB's with high rates in 2009 had low rates in 2010 and vice versa. The scattergram is included as a descriptive qualitative visual display only, with confidence intervals for each point not shown.

\section{Notification and hospitalisation}

\section{rates by age and ethnicity}

Based on Episurv data, the age distribution of notifications and hospitalisations for influenza $A\left(\mathrm{H}_{1} \mathrm{~N}_{1}\right)$ infections in 2010 was very similar to 2009 (Figure 3). As in 2009, the highest cumulative rates of notification and hospitalisation were in children under five years of age (92.9 and 58.2 cases per 100,000 population respectively). The overall hospitalisation rates were about a third lower in 2010 compared with 2009. The overall notification rate in 2010 was just over half of the 2009 rate. Notification and hospitalisation rates declined from 2009 to 2010 in all age groups, with relatively greater reductions in the age group of 0-19 year-olds.

The ethnicity distribution of notifications and hospitalisations due to influenza $\mathrm{A}\left(\mathrm{H}_{1} \mathrm{~N}_{1}\right)_{2009}$ infection in 2010 was markedly different from the one in 2009. Although highest rates in both years were seen in Pacific and Mãori populations, their rates dropped relative to the

\section{FIGURE 3}

Notification and hospitalisation rates for influenza $\mathrm{A}(\mathrm{H} 1 \mathrm{~N} 1)$ by age group $(\mathrm{A}, \mathrm{B})$ and ethnicity $(\mathrm{C}, \mathrm{D})$, stratified by year, New Zealand, 2009 and 2010

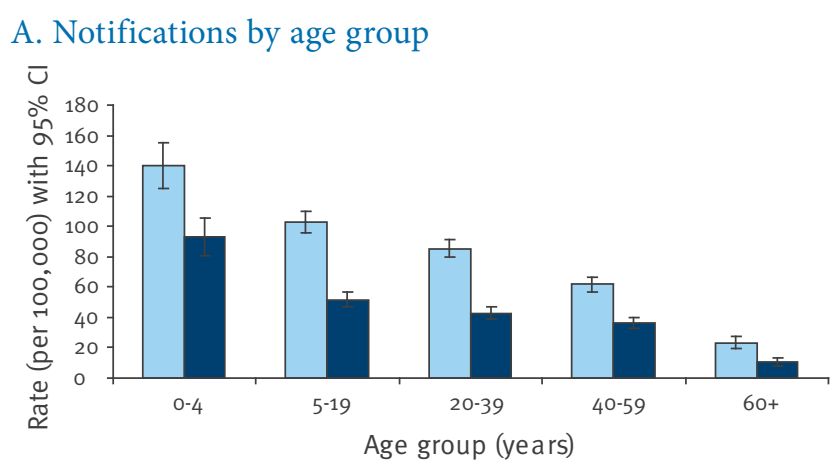

B. Hospitalisations by age group

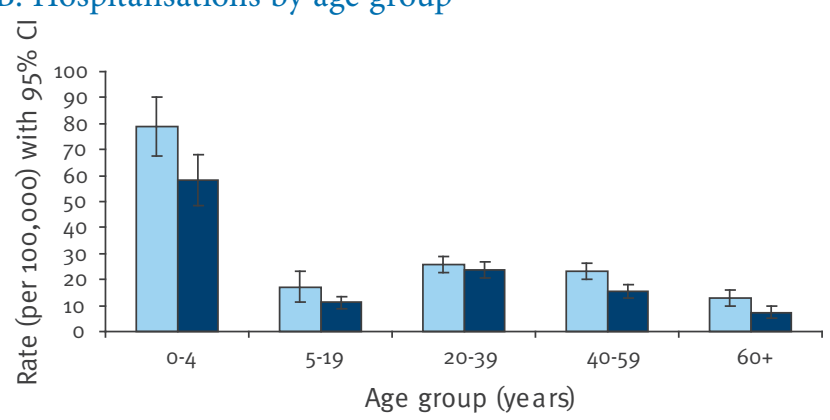

C. Notifications by ethnicity (age-adjusted)

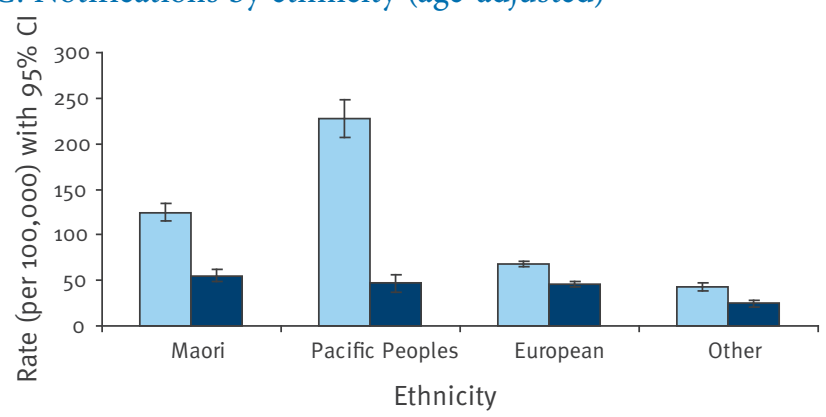

D. Hospitalisations by ethnicity (age-adjusted)

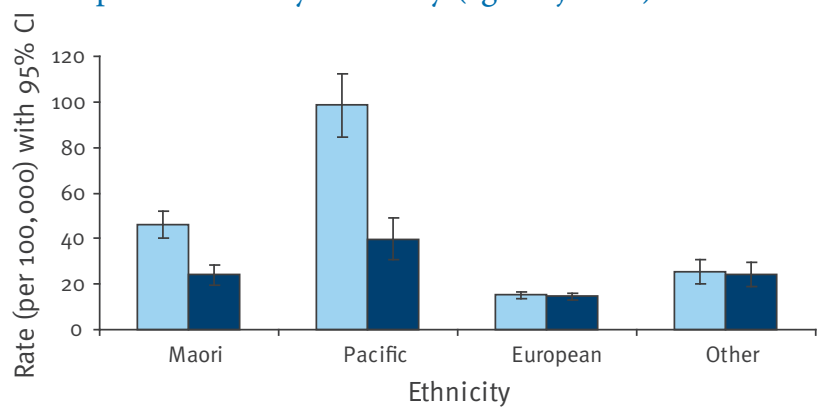

$\square 2009 \square 2010$

$\mathrm{Cl}$ : confidence interval. 
groups European and Other (Figure 3). In comparison to the European ethnic group, the rate ratio for Pacific Peoples in 2010 was 1.6 (95\% confidence interval (Cl): 1.3-1.9) for hospitalisation and 1.0 (95\% Cl: 0.8-1.2) for notification. This is much lower than the hospitalisation rate ratio of $4.6(95 \% \mathrm{Cl}: 4.2-5.1)$ and notification rate ratio of $3.4(95 \% \mathrm{Cl}: 3.0-3.7)$ in 2009. The Māori hospitalisation rate ratio of $1.8(95 \% \mathrm{Cl}: 1.6-2.0)$ and notification rate ratio of 1.2 ( $95 \% \mathrm{Cl}: 1.1-1.4)$ in 2010 showed a lesser reduction compared with those of 2.5 (95\% Cl: $2.3-2.7)$ and 1.8 (95\% Cl: 1.7-2.0) in 2009, respectively.

\section{Immunisation coverage and immunity}

Data are based on the results of the influenza $A\left(H_{1} N_{1}\right)_{2009}$ seroprevalence study conducted in 2009-10 [6] and claims received by the Ministry of Health from GPs for immunisations given on the subsidised programme. These are likely to be underestimates as the number of claims yet to be received and the number of people who purchased the vaccine privately is unknown.

A minimum of $1,046,000$ doses of the seasonal trivalent influenza vaccine were distributed in New Zealand in the 2010 season. Over 624,000 claims have been received up to end of October 2010 for the subsidised programme. In that year a considerable number of doses must have been purchased privately to explain that stocks were exhausted and had to be replenished. Table 2 shows numbers of persons with estimated levels of immunity and immunisation for five age groups.

\section{Discussion}

Impact of the 2010 influenza pandemic

The second year of pandemic influenza $A\left(\mathrm{H}_{1} \mathrm{~N}_{1}\right)_{2009}$ in New Zealand produced an epidemic curve similar in shape to the first wave, of about half to two thirds the size, and starting one month later in the winter. Multiple surveillance systems showed that the influenza $\mathrm{A}\left(\mathrm{H}_{1} \mathrm{~N}_{1}\right)_{200}$ incidence increased markedly in July 2010, peaked in mid-August and then declined. The national influenza wave lasted 15 weeks in 2009 as well as in 2010. It comprised multiple waves of activity at the district level that had a duration of about five weeks.

The second year of pandemic influenza $A\left(\mathrm{H}_{1} \mathrm{~N}_{1}\right)_{2009}$ again showed marked geographic heterogeneity. There was a weak negative correlation of infection rates in 2010 relative to 2009 . This finding supports the hypothesis that areas that were more affected in 2009 were protected to a certain extent in 2010. If this was not the case, we would expect (as we see for most diseases) that rates from one year to the next would be highly positively correlated because patterns of vulnerability tend to persist. Regional variations of influenza $A\left(\mathrm{H}_{1} \mathrm{~N}_{1}\right)_{2009}$ infections were also observed in 2009 in clinical surveillance as well as an influenza $A\left(\mathrm{H}_{1} \mathrm{~N}_{1}\right) 2009$ serosurvey $[2,3,6]$. It is possible that this variability allowed areas (mainly rural and small urban areas) with low pandemic influenza $\mathrm{A}\left(\mathrm{H}_{1} \mathrm{~N}_{1}\right)_{2009}$ activity to maintain more susceptible populations and to sustain more influenza $A\left(\mathrm{H}_{1} \mathrm{~N}_{1}\right) 2009$ infections and transmission in 2010 than in 2009.

While the hospitalisation rates for influenza in 2010 (16.7 per 100,000) were lower than in 2009 (23.5 per 100,000 ), the proportion of hospitalised influenza cases was higher in 2010 than in 2009. In addition, the proportion of hospitalised cases admitted to ICUs was higher in 2010. The reasons for these differences are not clear. There has been no obvious change in the severity of pandemic influenza $A\left(\mathrm{H}_{1} \mathrm{~N}_{1}\right)_{2009}$ disease or the thresholds for hospital and ICU admission. However, there was less pressure on hospital and ICU bed availability this year. It is also possible that there was a greater awareness of pandemic influenza $A\left(\mathrm{H}_{1} \mathrm{~N}_{1}\right)_{2} 009$ as a contributing factor to severe respiratory disease, and therefore higher likelihood of laboratory testing, hospitalisation and ICU admission.

The age distribution of influenza $A\left(\mathrm{H}_{1} \mathrm{~N}_{1}\right) 2009$ infections in 2010 was broadly similar to 2009 with highest rates in children under the age of five years. Hospitalisation rates declined significantly for most age groups, except for the 20-39-year-olds. This decline was particularly marked for children of 5-19 years although notification rates were still higher in

TABLE 2

Influenza immunity levels by age group, New Zealand, 2010

\begin{tabular}{|l|c|c|c|c|}
\hline $\begin{array}{l}\text { Age group } \\
\text { (years) }\end{array}$ & $\begin{array}{c}\text { Baseline immunity } \\
\mathrm{n}(\% \text { of population) }\end{array}$ & $\begin{array}{c}\text { Immunity following 2009 } \mathrm{H}_{1 \mathrm{~N} 1^{\mathrm{a}}} \\
\mathrm{n}(\% \text { of population) }\end{array}$ & $\begin{array}{c}\text { Immunisation 2010 } \\
\text { (pre-second wave) }^{\mathrm{b}} \\
\mathrm{n}(\% \text { of population) }\end{array}$ & $\begin{array}{c}\text { Total immunity 2010 } \\
\text { (pre-second wave) }^{\mathrm{b}} \\
\mathrm{n}(\% \text { of population) }\end{array}$ \\
\hline $1-4$ & $18,303(6.1 \%)$ & $88,515(29.5 \%)$ & $30,023(10.0 \%)$ & $109,818(36.6 \%)$ \\
\hline $5-19$ & $127,665(14.0 \%)$ & $425,853(46.7 \%)$ & $27,523(3.0 \%)$ & $440,443(48.3 \%)$ \\
\hline $20-39$ & $86,485(7.5 \%)$ & $255,995(22.2 \%)$ & $44,089(3.8 \%)$ & $290,589(25.2 \%)$ \\
\hline $40-59$ & $75,026(6.5 \%)$ & $233,159(20.2 \%)$ & $105,968(9.2 \%)$ & $317,419(27.5 \%)$ \\
\hline $60+$ & $169,401(22.6 \%)$ & $185,891(24.8 \%)$ & $416,832(55.6 \%)$ & $499,207(66.6 \%)$ \\
\hline
\end{tabular}

a Seroprevalence study.

${ }^{b}$ Immunisation claims 2010.

c Estimated total immunity assuming vaccination independently distributed in age group. 
children aged 519 years. This probably reflected a feature of the 2009 pandemic which caused relatively mild disease in children aged 5-19 years. By contrast, the ethnicity distribution of influenza $A\left(\mathrm{H}_{1} \mathrm{~N}_{1}\right)$ infections in 2010 changed markedly compared with 2009. Rates for Pacific and Māori populations remained significantly higher than for the groups European and Other, but the disparity was far less pronounced. These changes in the age and ethnicity distribution of the disease may reflect immunity from a combination of sources, including immunisation and natural infection (see impact of interventions below).

Reasons for ethnic differences in hospitalisation may include a higher incidence of infection in Pacific and Māori peoples, a higher prevalence of co-morbidities (such as asthma and diabetes), unfavourable environmental factors (such as household crowding and poor quality housing), behavioural differences in responding to influenza, differences in socio-cultural-economic status, differences in health service utilisation and increased genetic susceptibility [12]. Further study on the contributing factors to ethnic differences in the risk of influenza $A\left(\mathrm{H}_{1} \mathrm{~N}_{1}\right)_{2009}$ infection and severe disease is underway in New Zealand.

\section{New Zealand experience compared with other southern hemisphere countries} When the experience with the 2010 winter influenza season in New Zealand was compared to other temperate southern hemisphere countries such as Australia, South Africa and South America, they shared the common features that the influenza season started later and overall influenza activity was lower in 2010 than in 2009, with regional variation observed [13].

Most of the New Zealand isolates were antigenically and genetically closely related to the pandemic influenza $A\left(H_{1} N_{1}\right) 2009$ vaccine candidate $A / C a l i f o r n i a / 7 / 2009-$ like strain. However, a genetic variant with the dual haemagglutinin mutations $\mathrm{E}_{391} \mathrm{~K}$ and N142D emerged in Singapore in early 2010 and has subsequently spread through Australia and New Zealand in the 2010 winter period [11]. As of mid-October 2010, it appears that this genetic variant has not resulted in significant antigenic changes that would make the current vaccine less effective.

The pandemic influenza $A\left(\mathrm{H}_{1} \mathrm{~N}_{1}\right) 2009$ strain predominated with some seasonal influenza $A\left(\mathrm{H}_{3} \mathrm{~N}_{2}\right)$ and $B$ viruses in New Zealand and Australia. In Chile, the most frequently detected virus has been seasonal influenza $A\left(\mathrm{H}_{3} \mathrm{~N}_{2}\right)$ and in South Africa influenza B.

\section{Impact of interventions}

Community-based interventions to reduce the impact of pandemic influenza $A\left(\mathrm{H}_{1} \mathrm{~N}_{1}\right)_{2} 009$ included immunisation and continuing promotion of respiratory and hand hygiene. Parallel interventions included the provision of free antiviral drugs as well as asking sick persons to stay away from school or work and seek early medical advice. Uptake of the seasonal vaccine in 2010 was higher than in previous years although the proportions estimated to have been immunised remain low at around $24 \%$. The age distribution of influenza $A\left(H_{1} N_{1}\right) 2009$ in 2010 was consistent with estimated patterns of immunity in the population with higher disease rates in 20-39-year-old adults corresponding to their relatively low levels of immunity [14]. High levels of immunisation of those aged 60 years and older probably contributed to the large decline in disease rates in this age group in 2010 relative to their already low risk in 2009 [14]. The overall impact of these interventions requires further evaluation.

\section{Implications for northern hemisphere}

Many of the lessons from the first pandemic wave in the southern hemisphere in 2009 still apply[14] . While careful monitoring is required for emerging new antigenic variants the current circulating virus is now a familiar virus and we also have the benefits of an effective vaccine. The description of the second wave of the pandemic in New Zealand, a temperate southern hemisphere country, has some implications for the influenza season in the northern hemisphere. Although the second wave affected smaller numbers in New Zealand overall, it had a higher impact in some regions and populations with less immunity (from the first wave). Vulnerable populations continue to include indigenous people, the young, pregnant woman, and those with serious chronic health conditions [14]. There was no indication of a change in virulence of the virus.

The New Zealand experience also raises the question as to whether the phenomena we have seen with this virus in 2010 are best described as the second wave of a pandemic or the first year of a new seasonal influenza virus. In past pandemics (certainly in 1918), the second and subsequent waves of infection were often characterised as out of season and with markedly higher virulence compared with seasonal viruses [15] The pandemic influenza $A\left(\mathrm{H}_{1} \mathrm{~N}_{1}\right)_{2009}$ virus has not shown those pandemic features in 2010. It appears to have completely displaced seasonal influenza $A\left(\mathrm{H}_{1} \mathrm{~N}_{1}\right)$ virus in 2010 in New Zealand.

\section{Strengths and limitations of New \\ Zealand surveillance data}

The influenza surveillance systems in New Zealand provide information on disease, hazards, determinants and interventions related to this infectious agent [16] Several of these systems have been particularly effective at providing strategy-focused information to characterise the pandemic, notably GP sentinel surveillance (which includes virological surveillance), hospitalisation data, and the national serological survey. A full investigation is still needed to assess the overall adequacy of influenza surveillance in New Zealand, particularly control-focussed surveillance aimed at supporting the containment phase of pandemic management, but overall the systems stood up well to the challenges posed by the pandemic. 


\section{Acknowledgements}

The national influenza surveillance is funded by the Ministry of Health who kindly permitted the use of relevant data for publication. Our special thanks to the GPs and nurses, the public health unit coordinators and the participating virology laboratories in Auckland, Christchurch, Waikato, Wellington, and WHO National Influenza Centre at ESR

\section{References}

1. Lopez L, Huang QS. Influenza in New Zealand in 2009. Client report FW10019. Upper Hutt: Institute of Environmental Science and Research; March 2010. Available from: http:// www.surv.esr.cri.nz/PDF surveillance/Virology/FluAnnRpt/ InfluenzaAnn2009.pdf

2. Baker MG, Wilson N, Huang QS, Paine S, Lopez L, Bandaranayake $D$, et al. Pandemic influenza $A\left(\mathrm{H}_{1} \mathrm{~N}_{1}\right) v$ in $\mathrm{New}$ Zealand: the experience from April to August 2009. Euro Surveill. 2009;14(34):pii=19319. Available from: http://www. eurosurveillance.org/ViewArticle.aspx?Articleld=19319

3. Centers for Disease Control and Prevention (CDC). Surveillance for the 2009 pandemic influenza $A\left(\mathrm{H}_{1} \mathrm{~N}_{1}\right)$ virus and seasonal influenza viruses - New Zealand, 2009. MMWR Morb Mortal Wkly Rep. 2009;58(33):918-21.

4. Baker MG, Thornley CN, Mills C, Roberts S, Perera S, Peters J, et al. Transmission of pandemic A/H1N1 2009 influenza on passenger aircraft: retrospective cohort study. BMJ. 2010;340:C2424.

5. Hall RJ, Peacey MP, Ralston JC, Bocacao J, Ziki M, Gunn $W$, et al. Pandemic influenza $A\left(\mathrm{H}_{1} \mathrm{~N}_{1}\right) v$ viruses currently circulating in New Zealand are sensitive to oseltamivir. Euro Surveill. 2009;14(30):pii=19282. Available from: http://www. eurosurveillance.org/ViewArticle.aspx?Articleld=19282

6. Bandaranayake D, Huang QS, Bissielo A, Wood T, Mackereth G, Baker MG,et al. Risk Factors and Immunity in a Nationally Representative Population following the 2009 Influenza $\mathrm{A}\left(\mathrm{H}_{1} \mathrm{~N}_{1}\right)$ Pandemic. PLoS One. 2010;5(10):e13211.

7. Huang QS. Recommendation for seasonal influenza vaccine composition for New Zealand 2011. Client report FW10088. Upper Hutt: Institute of Environmental Science and Research; October 2010. Available from: http://www.surv.esr.cri.nz/ PDF_surveillance/Virology/FluVac/FluVac2011.pdf

8. Huang QS, Lopez, L.D., McCallum, L., Adlam B. Influenza surveillance and immunisation in New Zealand, 1997-2006. Influenza Other Respi Viruses. 2008; 2(4):139-45.

9. World Health Organization Collaborating Centre for influenza at CDC Atlanta. CDC protocol of realtime RTPCR for influenza A ( $\left.\mathrm{H}_{1} \mathrm{~N}_{1}\right)$. Geneva: WHO; 6 October 2009. Available from: http://www.who.int/csr/resources/publications/swineflu/ CDCRealtimeRTPCR_SwineH1Assay-2009_20090430.pdf

10. PIMMRG. Report for the Minister of Health from the pandemic influenza mortality and morbidity review group. Wellington: Ministry of Health; October 2010. Available from: http://www. pmmrc.health.govt.nz/moh.nsf/pagescm/7745/\$File/reportpandemix-influenza-mortality-morbidity-review-group.pdf.

11. Barr IG Cui L, Komadina N, Lee RT, Lin RT, Deng Y, Caldwell $\mathrm{N}$, et al. A new pandemic influenza $A\left(\mathrm{H}_{1} \mathrm{~N}_{1}\right)$ genetic variant predominated in the winter 2010 influenza season in Australia, New Zealand and Singapore. Euro Surveill. 2010;15(42):pii=19692. Available from: http://www. eurosurveillance.org/ViewArticle.aspx?Articleld=19692

12. La Ruche G, Tarantola A, Barboza P, Vaillant L, Gueguen J, Gastellu-Etchegorry M, et al. The 2009 pandemic $\mathrm{H}_{1} \mathrm{~N}_{1}$ influenza and indigenous populations of the Americas and the Pacific. Euro Surveill. 2009;14(42):pii=19366. Available from: http://www.eurosurveillance.org/ViewArticle. aspx?Articleld $=19366$

13. World Health Organization. Influenza update - 8 October 2010. Geneva: WHO: 8 October 2010. Available from: http://www. who.int/csr/disease/influenza/2010_10_08_GIP_surveillance/ en/print.html

14. Baker MG, Kelly H, Wilson N. Pandemic $\mathrm{H}_{1} \mathrm{~N}_{1}$ influenza lessons from the southern hemisphere. Euro Surveill. 2009;14(42): pii=19370. Available from: http://www. eurosurveillance.org/ViewArticle.aspx?Articleld=19370

15. Miller MA, Viboud C, Balinska M, Simonsen L. The signature features of influenza pandemics--implications for policy. $\mathrm{N}$ Engl J Med. 2009;360(25):2595-8.

16. Baker MG, Easther S, Wilson N. A surveillance sector review applied to infectious diseases at a country level. BMC Public Health. 2010;10:332. 